\section{Reactivity of Thiophthenes; a Theoretical Study}

\author{
N. Trinajstić and Z. Majerski
}

Institute "Rudjer Bošković", Zagreb, Croatia, Yugoslavia

(Z. Naturforschg. 22 a, 1475-1476 [1967] ; received 15 July 1967)

There are three possible isomeric thiophthenes, namely 1,4-thiophthene, 1,5-thiophthene, and 1,6-thiophthene, shown in the Figure ${ }^{*}$. Several workers ${ }^{1-3}$ have reported the syntheses and properties of these thiophthenes. We have investigated these molecules re-

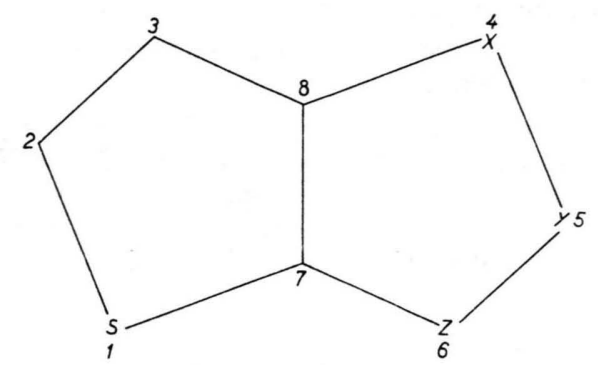

Fig. 1. Atomic skeletal structure and numbering of atoms for the three studied thiophthenes:

$\begin{array}{ll}\text { 1. } \mathrm{X}=\mathrm{S}, \mathrm{Y}=\mathrm{Z}=\mathrm{C} & \text { (1,4-thiophthene), } \\ \text { 2. } \mathrm{Y}=\mathrm{S}, \mathrm{X}=\mathrm{Z}=\mathrm{C} \quad & \text { (1,5-thiophthene), } \\ \text { 3. } \mathrm{Z}=\mathrm{S}, \mathrm{Y}=\mathrm{X}=\mathrm{C} & \text { (1,6-thiophthene). }\end{array}$

garding substitution reactions, being interested in predicting the positions of electrophilic, nucleophilic, or radical attack. In doing this we have followed the so called "static method" 4 originated by WhELand and PAuling $^{5}$, and later extended by using pertubation theory as laid down by Courson ${ }^{6}$, and Coulson and Longuet-Higgins ${ }^{\text {? }}$.

The aromatic substitution reactions are very complex, and each of the earlier mentioned substitutions is a several stages process. However, because in the electrophilic and nucleophilic substitutions, the attacking reagents are usually charged, we can expect a correlation between the electron density and the attacking charged species. Since the radical species are neutral, we cannot expect any correlation with electron density. But, the correlation with the free valence proved to be quite successful. It is also possible to cor-

* These molecules are also referred to as thieno $(3,2-\mathrm{b})$ thiophene, thieno $(3,4-\mathrm{b})$ thiophene, and thieno $(2,3-\mathrm{b})$ thiophene.

1 V. V. Ghaisas and B. D. Tilak, Proc. Indian Acad. Sci. 39 A, 14 [1954].

2 S. Gronowitz, U. Ruden, and B. Gestblom, Arkiv Kemi 20, 297 [1963].

3 H. Wynberg and D. J. Zwanenburg, Tetrahedron Letters 1967, 761.

4 K. Higasi, H. Baba, and A. Rembaum, Quantum Organic Chemistry, Interscience Publishers, New York 1965, chap. 11.

5 G. W. Wheland and L. Pauling, J. Am. Chem. Soc. 57, 2086 [1935].

6 C. A. Coulson, Discussion Faraday Soc. 2, 9 [1947]. relate the reactivity of the bond with the bond order value, and predict the most reactive bonds.

We have therefore applied the molecular orbital method in the framework of the PARISER-PARR-Pople theory 8,9 to calculate the $\pi$-electron densities, the $\pi$-bond orders, and the free valence indices, shown in Table 1, 2, and 3. The following one-electron core integrals are used in the calculation: $\beta_{\mathrm{CC}}=-2.395$ $\mathrm{eV}^{10}, \beta_{\mathrm{CS}}=-2.000 \mathrm{eV}^{11}$, and $\delta W_{\mathrm{S}}=-8.840 \mathrm{eV}^{12}$. The two-electron Counomb integrals were evaluated using a Mataga-Nishrmoto-type approximation ${ }^{13}$. All $\mathrm{C}-\mathrm{C}$ bonds were taken to be equal to $1.40 \AA$, and $\mathrm{C}-\mathrm{S}$ bonds to $1.74 \AA$ for purposes of calculation.

\begin{tabular}{cccc}
\hline Atoms & 1,4-thiophthene & 1,5-thiophthene & 1,6-thiophthene \\
\hline 1 & 1.7597 & 1.8064 & 1.7644 \\
2 & 1.0627 & 1.0466 & 1.0796 \\
3 & 1.0904 & 1.0798 & 1.0678 \\
4 & 1.7596 & 1.0918 & 1.0678 \\
5 & 1.0627 & 1.7058 & 1.0796 \\
6 & 1.0904 & 1.1280 & 1.7644 \\
7 & 1.0874 & 1.0688 & 1.0840 \\
8 & 1.0874 & 1.0728 & 1.0924 \\
\hline
\end{tabular}

Table 1. $\pi$-electron Densities.

\begin{tabular}{cccc}
\hline Atoms & 1,4-thiophthene & 1,5-thiophthene & 1,6-thiophthene \\
\hline $1-2$ & 0.4066 & 0.3558 & 0.3854 \\
$1-7$ & 0.3612 & 0.3054 & 0.3804 \\
$2-3$ & 0.8210 & 0.8672 & 0.8388 \\
$3-8$ & 0.4921 & 0.4048 & 0.4620 \\
$4-5$ & 0.4066 & 0.4532 & 0.8388 \\
$4-8$ & 0.3612 & 0.7188 & 0.4620 \\
$5-6$ & 0.8210 & 0.4284 & 0.3854 \\
$6-7$ & 0.4921 & 0.7530 & 0.3806 \\
$7-8$ & 0.6871 & 0.4954 & 0.6954 \\
\hline
\end{tabular}

Table 2. $\pi$-bond Orders.

It is clear from Table 4 that position 3 and 6 in 1,4-thiophthene, position 4 and 6 in 1,5-thiophthene, and position 2 and 5 in 1,6-thiophthene (2-acetamido1,6-thiophthene ${ }^{14}, \quad 2$-thioacetamido-1,6-thiophthene ${ }^{14}$ ) are the most reactive sites for electrophilic reagents. Positions 2 and 5 in 1,4-thiophthene, positions 2 and 3

7 C. A. Coulson and H. C. Longuet-Higgins, Proc. Roy. Soc. London A 191, 39 [1947], A 192, 16 [1947].

8 R. PAriser and R. G. PARr, J. Chem. Phys. 21, 466, 767 [1953].

9 J. A. Pople, Trans. Faraday Soc. 49, 1375 [1953].

10 T. E. Peacock, Electronic Properties of Aromatic and Heterocyclic Molecules, Academic Press, London 1965.

11 N. Solony, F. W. Birss, and J. B. Greenshields, Can. J. Chem. 43, 1569 [1965].

12 R. J. Wratten and M. Ali, Trans. Faraday Soc., in press. 13 N. Mataga and K. Nishimoto, Z. Phys. Chem. Frankfurt 13, 140 [1957].

14 V. G. Zhiryakov and P. I. Abramenko, Chem. Abstr. 62, $10440 \mathrm{~h}, 10441$ a [1965]. 


\begin{tabular}{cccc}
\hline Atoms & 1,4-thiophthene & 1,5-thiophthene & 1,6-thiophthene \\
\hline 1 & - & - & - \\
2 & 0.5044 & 0.5090 & 0.5078 \\
3 & 0.4189 & 0.4600 & 0.4312 \\
4 & - & 0.5600 & 0.4312 \\
5 & 0.5044 & - & 0.5079 \\
6 & 0.4189 & 0.5506 & - \\
7 & 0.1916 & 0.1782 & 0.2756 \\
8 & 0.1916 & 0.1130 & 0.1126 \\
\hline
\end{tabular}

Table 3. Free Valence Indices.

\begin{tabular}{ccccc}
\hline & \multicolumn{4}{c}{ Reaction (Position) } \\
\cline { 2 - 5 } Compound & $\begin{array}{c}\text { electro- } \\
\text { philic }\end{array}$ & $\begin{array}{c}\text { nucleo- } \\
\text { philic }\end{array}$ & radical & addition \\
\hline 1,4-thiophthene & 3,6 & 2,5 & 2,5 & $\left\{\begin{array}{l}2-3 \\
5-6 \\
2-3\end{array}\right.$ \\
1,5-thiophthene & 6,4 & 2,3 & 4,6 & 2,5 \\
1,6-thiophthene & 2,5 & 3,4 & $\left\{\begin{array}{l}2-3 \\
4-5\end{array}\right.$ \\
\hline
\end{tabular}

Table 4. The Prediction of Reactivity of Thiophthenes.

15 R. Gompper, E. Kutter, and W. Toepfl, Ann. Chem. 659, 90 [1962].

16 R. Gompper and E. Kutter, Angew. Chem. 74, 251 [1962].

17 Ya. L. Gol'dfarb and V. P. Litvinov, Izv. Akad. Nauk SSSR, Ser. Khim. 1963, 1621.

18 O. Dann and W. Dimmling, Chem. Ber. 87, 373 [1954]. in 1,5-thiophthene (1,5-thiophene-2-carboxylic acid $\left.{ }^{3}\right)$, and positions 3 and 4 in 1,6-thiophthene (1,6-thiophthene-3,4-diol ${ }^{15,16}$ ) are the possible sites for nucleophilic attack. Positions 2 and 5 in 1,4-thiophthene, positions 4 and 6 in 1,5-thiophthene, and positions 2 and 5 in 1,6-thiophthene are the most reactive positions for radical attack. There is a vast amount of data concerning radical reactions available in the literature. It appears that these compounds favour radical reactions. We cite a few examples: 2-methyl-1,4-thiophthene ${ }^{2}$, 2,5-dimethyl-1,4-thiophthene ${ }^{17}$, 4,6-dimethyl-1,5-thiophthene ${ }^{18,19}$, 2-ethyl-1,6-thiophthene ${ }^{20}$, and 2,5-diethyl-1,6-thiophthene ${ }^{21}$. Finally, the most reactive bonds in all three compounds are the next nearest bonds to sulphur atoms.

We are in the process of developing a more sophisticated approach, but the results presented in this note suggest that even a simple approach such as we have adopted can, to some extent, be useful in the study of the reactivities of organosulphur molecules.

Acknowledgement: We thank Dr. A. Hinchliffe for helpful discussions.

19 E. Imoto and R. Notoyama, Chem. Abstr. 1955, $4620 \mathrm{~d}$.

20 Y. L. Gol'dfarb and V. P. Litvinov, Izv. Akad. Nauk SSSR, Ser. Khim. 1963, 343.

21 V. P. Litvinov and Ya. L. Gol'dfarb, Izv. Akad. Nauk SSSR, Ser. Khim. 1963, 2183.

\section{BERICHTIGUNG}

Zu F. Lohmann, Fermi-Niveau und Flachbandpotential von Molekülkristallen aromatischer Kohlenwasserstoffe, Z. Naturforschg. 22 a, 843 [1967].

Auf S. 844, rechte Spalte, in der letzten Gleichung muß es heißen:

$$
U_{\mathrm{FB}}=\cdots-4,48+4,17=-0,3 \mathrm{~V} \text {. }
$$

